\title{
Research Paper: Analysis of the Participation of NGOs and Cities of Mashhad in the Field of Social and Cultural Practices
}

\author{
Maryam Eskafi $^{1 *}$ (D), Reza Abbaspour ${ }^{2}$ (D) \\ 1. Department of Social Science, School of Humanities, Gonabad Branch, Islamic Azad University, Gonabad, Iran. \\ 2. Department of Islamic Juricprudence, Mashhad Branch, Islamic Azad University, Mashhad, Iran.
}

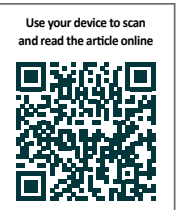

Crtation Eskafi M, Abbaspour R. Analysis of the Participation of NGOs and Cities of Mashhad in the Field of Social and Cultural Practices. Journal of Research and Health. 2020; 10(6):403-410. http://dx.doi.org/10.32598/JRH.10.6.1368.6

: http://dx.doi.org/10.32598/JRH.10.6.1368.6

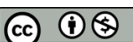

Article info:

Received: 07 Oct 2018

Accepted: 24 Nov 2019

Publish: 01 Nov 2020

\section{Keywords:}

Participation, Nongovernmental organization, Cities, Social and cultural practices

\begin{abstract}
A B S TRACT
Background: The Iranian society should appreciate health and well-being, food security, and social security in 2026. It is strongly related to the tasks of Nongovernmental Organizations (NGOs), concerning its extent. Therefore, this research aimed to identify fundamental factors in the active involvement of NGOs and the Mashhad municipality, in sociocultural programs.

Methods: This research used a qualitative approach. Also, the statistical population included the NGOs that have at least once cooperated with the municipality. The study sample recruited using a purposeful sampling technique. The collected data were generated through the design of triangulation. Subsequently, 159 concepts, 40 subcategories, and 18 items were obtained.

Results: The results indicated that the maximum mutual participation is the only interaction type that could fully satisfy both the municipality and NGOs.

Conclusion: A misleading, slogan-based, result-oriented participation exists between these organizations, because the principles of involvement are not observed.
\end{abstract}

\section{Introduction}

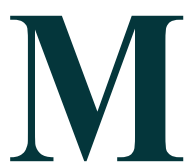

ashhad is one of the popular towns with an annual increase in population. This fast development alerts the municipal executives, as demographic growth is accompanied by a rise in the essential requirements of residents. Sociocultural needs are one of the most important ones. According to studies, "one of the severe and basic criticisms ad- dressed by urban executives is the absence of attention to the sociocultural elements in development plans".

That is why social specialists and researchers think that despite massive investment and sources in Iranian cities, there has been no improvement in the equality of life, compared with the previous and even the residents' constraints and issues [1]. This problem established a gap between the circumstances of life and desirable situations.

\footnotetext{
* Corresponding Author:

Maryam Eskafi, PhD.

Address: Department of Social Science, School of Humanities, Gonabad Branch, Islamic Azad University, Gonabad, Iran.

Phone: +98 (915) 3221003

E-mail: meskafi@yahoo.com
} 
Evidence indicated low turnout between the individuals and the municipality. The participation idea is strongly related to the concept of citizenship, in which citizens' rights, duties, roles, and obligations are particular and internalized. Thus, true and active citizenship could materialize through the involvement of all the members of society. The World Bank considers the absence of involvement as the primary reason why developing nations fail to enhance [2]. From Tocqueville's point of perspective, cooperation between government and nongovernmental organizations (NGOs) is an instruction for advancement and empowers weak governments. Numerous studies in other nations [3-7] alleviate the attention to involvement having the ability to promote public ability to decrease economic and managerial burden [8].

Also, many studies within and outside Iran [9-11] highlighted the basic function of such organizations. In most of the studies, researchers have access to this topic using residents rather than NGOs as the unit of assessment [12, 13]. Besides, several studies have been carried out on the role of organizations in different subjects [14, 15], but none of them has specifically pointed to the involvement of NGOs and their contribution to sociocultural programs. However, the original phenomena before communication are involvement and its frequency and the reasons for its absence, which have not been discussed in detail.

Moreover, we regarded research on most religious-cultural organizations, such as mosques. On the other side, the investigators observed contradictions in the outcomes of multiple studies on the participation level of people with the municipality. These contradictions indicated the absence of clarity in the state of government involvement and inspired the investigator to conduct the study. The conceptual framework of the present research is focused on decentralization, excellent urban governance, human factors, and the Parsons theory of action.

Based on the concept and process of successful urban governance, involvement between government and NGOs is necessary to form this form of governance, the most significant criteria of which include involvement, compliance with law, the transparency of performance, flexibility, noncentric consensus, justice, effectiveness, and responsiveness. These are exactly the elements that the state (here the municipality) and the NGOs need to participate.

The sort of involvement between the NGOs and the government shows the distinction in the type of partnership between distinct nations, according to the current literature. The share and importance of these kinds of organizations is evident for the government. One of the primary objectives of founding NGOs is to provide individuals with different services. This sort of organization acts as a mediator between individuals and the government, and it makes the NGOs vital. Consequently, the government and NGOs are increasingly building a demanding relationship. The complexity and diversity of municipal relations with NGOs are explained based on what has been indicated in prior research.

The type of partnership is one of the most important variables in managing NGOs. The type of association could be obtained from the type of attitude towards involvement, pointing to the prior process-oriented studies and other kinds. Globally, this kind of perspective is the consequence of centralization, which has been considered as one of the issues of involvement. Because in this kind of perspective, the choice is from top to bottom and not vice versa. The only stance that contributes to the endogenous growth is from the bottom to the top. According to the Orbista theory [16], there is little space for individuals to participate in decision-making, in top to bottom stance, where authority is in the hands of the government.

So, execution is poor because the individuals have no incentive for collaboration. Besides, one of the best-known theories defines involvement as four phases of policy-making, execution, assessment, and the division of interests. Indeed, higher involvement in these four phases provides a stronger incentive to do so. Therefore, the investigators attempted to define the efficient factors in the involvement of the Mashhad municipality and NGOs through the study of organizations that contribute to municipal plans.

\section{Methods}

This research used a qualitative approach. The researcher (who is a staff member of the municipality) attempted to see the fact through participatory observation and in-depth interviews with the executives and experts of the municipalities and NGOs. The target group of this research included NGOs engaged in the field of sociocultural practices in Mashhad City. Also, the participants did not follow economic and political interests, and they have at least once worked with the municipality. The study sample was recruited through the purposive sampling method.

Moreover, the investigator performed interviews with three classifications of individuals to achieve the responses to the issues. First, we performed a group interview with seven participatory specialists to recognize the likely casual network. The interviewer subsequently altered the questions to conduct in-depth interviews with the second category, including four participating directors and experts. Then, the 
in-depth interviews were performed with seven NGO executives. Using the design of the triangulation, we obtained the convergence of different methods and data validity and reliability. In the final stage, the data were interpreted and analyzed and the final model was developed.

\section{Results}

\section{Contextual conditions}

\section{Unfavorable situation for collaborative work}

The result of the group interview showed that involvement could be individual or collective. In their activities, individuals exhibited certain features, such as the avoidance of accountability, thirst for authority, individual motivations, individualism, and lawlessness, which reflected individualism preference over collectivism. On the other side, the inappropriate context for involvement in culture, the absence of awareness, impatience, and seeking enthusiasm showed that the circumstances for involvement were unsatisfactory in either society or people. Therefore, these two subcategories expressed an undesirable condition for cooperative work that could be a subset of contextual circumstances.

\section{Becoming demotivated to participate in society}

After involvement, people also acquire experiences that may or may not be a determining factor in an ongoing cooperative job. These experiences may hurt the intrinsic motivations of individuals and disrupt external motivation. Also, some behaviors disturb the external motivation, which could be seen as a result of this sort of collaboration.

\section{Incompatibility of goals between and within NGOs}

The incompatibility of objectives can happen because of two reasons: one the absence of coordination between and within NGOs, and the other is a performance that leads some NGOs to deviate from their purpose. Besides, the issues between and within NGOs act as another contextual factor affecting the magnitude of involvement. Disagreement between the political viewpoints of the members of the NGOs and the political, intellectual, and ideological categories not only creates disagreement between the members of the organization but also contributes to dispute within the NGOs, affecting their purpose and performance. The performance of the municipality by little economic assistance has developed unrealistic expectations in many individuals. In some instances, these expectations have led the members of the NGOs to have a materialistic view of their job or led individuals to join such organizations with this perspective. These two variables established the incompatibility of objectives between and within NGOs.

\section{Lack of a steady culture custodian in society}

Another problem is the absence of a constant culture custodian of NGOs in society, resulting in issues, such as abandoning other NGOs' involvement to engage in cultural programs, unloading this burden on the municipality, developing an extensive municipality, an established lack of institutional assistance, and extensive cultural job definition. On the other side, this deficiency has set the stage for the other two subcategories, namely inter and intraorganizational obstacles to NGOs. External organizational obstacles, such as various licensing organizations, location issues, licensing issues, uncertain support for NGOs owing to changes in management, safety measures, the absence of a union, and the lack of precise statistics from NGOs cause intra-organizational obstacles, such as the unrecognized and uncertain places of NGOs and uncertain position owing to frequent motion.

\section{Causal conditions}

Goal incompatibility between NGOs and municipality

In conflict sociology, incongruous objectives emerge from inconsistent values and roles resulting from variations in output amount and quality and perspective type. NGO is an informal, nongovernmental, and almost private organization that is nonprofitable and charitable and focuses on community profit. Therefore, NGOs work more efficiently, whereas quantity plays a much greater role than quality in governmental organizations, as they should be presented for assessment and selection. The number of respondents and the appearance in general are much more important than the style and type of job for organizations, such as the municipality.

They have a deep effect, however, the quality is more crucial for NGOs. The NGOs have a straightforward appearance and atmosphere, but they emphasize the performance depth and impact. Therefore, these two kinds of organizations are uncoordinated in their involvement. The municipality and other governmental organizations only recognize projects consisting of organizational objectives, but this uniformity of objectives does not exist between two distinct kinds of organizations with discrete performance and objectives. 


\section{Centralization}

Centralization is another significant factor that affects involvement. When leadership is centralized, the need is described from the bottom, based on neither the needs evaluation nor the community-based model, but from the top. When leadership is centralized, involvement is taste-based and does not require the maximum use of the expertise of all NGOs. With centralized management, NGOs' ideas and plans cannot be utilized and the engagement process may not be fully enforced, as the strategy is top-down and individuals are not engaged in decisionmaking and needs-determination. Centralized leadership is the decision-making process at the highest level of executives, where the fundamental needs of the lesser strata are not addressed. The fact that the needs are not based on the necessity of NGOs but are defined from the top authority disturbs the NGOs, as the main task of NGOs is to mediate between the government and the people and to communicate the needs from the bottom up. However, this will not occur with centralized leadership.

Limited political norms in the process of participation between NGOs and municipality

This category includes two subcategories: political orientation in the municipality and faith in NGO capacity.

The political leaning in the municipality has many characteristics, the most significant of which is the religious-political view. This perspective has led to the absence of assistance for music by clergymen in Mashhad City despite the concern of the individuals, the absence of attraction, the individuals do not adhere to the dress code, the bias of the individuals, and the distrust of the clergy. Another sort of inclination stems from distinct political viewpoints and results in the unwillingness of the municipality to ratify the contract, draw rigid lies, and change the schemes, plans, and viewpoints. The belief that NGOs are capable of doing so is another subcategory that involves the ideas of creating the authority of NGOs, fearing the effect of NGOs, and the need for NGOs to implement programs.

\section{Intervening conditions}

\section{Bureaucratic rationality}

According to interviews, bureaucratic rationality is one of the interfering and mediating circumstances for involvement. Bureaucratic rationality emerged in the subcategories of the lack of administrative assistance, complicated legislation, and regulations, and led NGOs to be dissatis- fied by administrative organizations, which according to interviews, play an intense damaging role in all of them.

\section{Lack of transparency}

One of the significant points of the interviews was that the problems, such as the incompetence of executives and the lack of awareness of cultural issues were observed in conferences, either during contract ratification or the execution of programs. These problems develop a subcategory of role ambiguity. On the other side, identifying the incompatibility laws with the middle rules upstream municipal programs and the absence of transparent guidelines are other considerations that are subsumed under the category of nontransparent participatory legislation. These subcategories together generate the category of nontransparency.

\section{Coping strategies}

As a result of the situation, NGOs, municipalities, and a group of managers and officials have implemented several types of coping strategies in the name of the beneficiaries as follows:

\section{Maximum mutual participation}

If both sides are satisfied with some of the plans, maximum mutual involvement will happen. The NGOs can attain their objectives without incurring any cost and with the assistance of the municipality and its equipments. Inversely, with the help of NGOs, the municipality can achieve one of the specified objectives following its purposes and guidelines, without any expense.

\section{No mutual cooperation}

Noncooperation is another reciprocal coping strategy. As stated in the interviews, one of its reasons is the municipality's situation for collaboration and involvement, which may be inconsistent with municipal objectives. Thus, the municipality removes those NGOs that collaborate with it. Another reason is that the NGOs may not feel the need to participate with governmental organizations, including the municipality, the strengths and weaknesses of their NGOs because of their stability and authority.

\section{Selective participation}

Selective involvement is one of the ways to cope with the municipality. That is, considering their requirements, NGOs cooperate in the projects, based on the documents and norms that are compatible with their objectives. Respondents said they did not have the same attitude towards nongovernmen- 
tal organizations. The unknown NGOs are not recognized but they are of interest to municipal executives.

\section{Compulsory participation}

Compulsory involvement is another coping strategy practiced by NGOs, concerning the municipality and other government agencies. The economic issues of NGOs are not solved by collaboration with a single organization, because of having no permits, constant salary, continuous financial support, and not having a particular plan for a long time. These problems may trigger structural, legal, and financial instability in their programs. Despite being unhappy with the municipality and other government agencies in their extractions, the NGOs have to participate.

\section{Stakeholder free ride participation}

This approach explains one of the stakeholders that exploits issues in an immortal manner between governmental organizations and NGOs. Various subcategories can represent in this category. This violence sometimes increases through favoritism, namely, through relationship rather than regulation. If for a long time some concepts of the NGOs are being studied, advertisements that incur financial and intellectual causes are dismissed. Various pretexts, and the NGOs are replicable instead of being performed by them, it is subsequently enforced by others. Another way is not to divide policymaking, the outcome of which is the benefit of stakeholders.

\section{Minimal participation}

The NGO executives feel that government agencies have handled them in different undesirable ways. The status of NGOs in society has stayed unknown and they do not play a part in planning with the municipality in participatory programs. The other unfavorable actions of NGOs are the reason for their minimal involvement. In many instances, the absence of economic assistance from government agencies in carrying out the projects has caused NGO members to leave their work and be frustrated. The sort of economic relationship with NGOs has led them to remain at the smallest stage in their relationship with government agencies.

\section{Slogan-based participation}

In this situation, there is no real involvement, but participants claim to have it; the primary reason is the ease of performance. There is no place for people in decision-making and policymaking. This category includes eight subcategories as follows: no involvement in budgeting, policy- making, efficiency and practice phases, involvement in lip service, incomplete involvement, reduced participation motivation in NGOs and individuals, and the disapproval of plans and the thoughts of NGOs. The comparison of these outcomes with the most conventional partnership definition indicates that there is no phase involvement and the NGO is compelled to engage with them.

\section{Maximum participation}

One of the NGOs' policies is maximum involvement. Based on the subcategories of interview, this category involves several types. The first type is compensation. Financial pressure is the second type. Also, the third and fourth types are effort and obey, respectively.

\section{Consequences}

\section{Inefficiency}

Another result of these policies is inefficiency resulting from subcategories, such as unscientific resources, interorganizational obstacles, welfare and living inequality, and uncertain job limits.

\section{Mutual dissatisfaction between NGOs and the municipality}

Mutual discontent is one of the implications of the two organizations' policies, which consists of three subcategories, namely these three causes. Mutual lack of confidence between the two organizations.

Unpleasant experiences among the parties, including ideas, such as results and negative experiences, mutual discontent, failure to fulfill mutual expectations, nonpartnership and non-exchange between municipalities and Semnan City, and the absence of common language.

\section{Discussion}

One of the sub-indicators of urban governance is involvement, which is one of the wide and thorough debates on sustainable development. Involvement as a good relationship can only be accomplished if both sides share common objectives [17]. Also, common objectives relies on the form of the point of perspective. The sort of the point of perspective derives from centralization, in which decision-making is from top to bottom, not from bottom to top.

The investigator created this theory through the group interview. Only the perspective from the bottom to the top contributes to endogenous growth. Managementcentered partnership is the common sort of relationship 


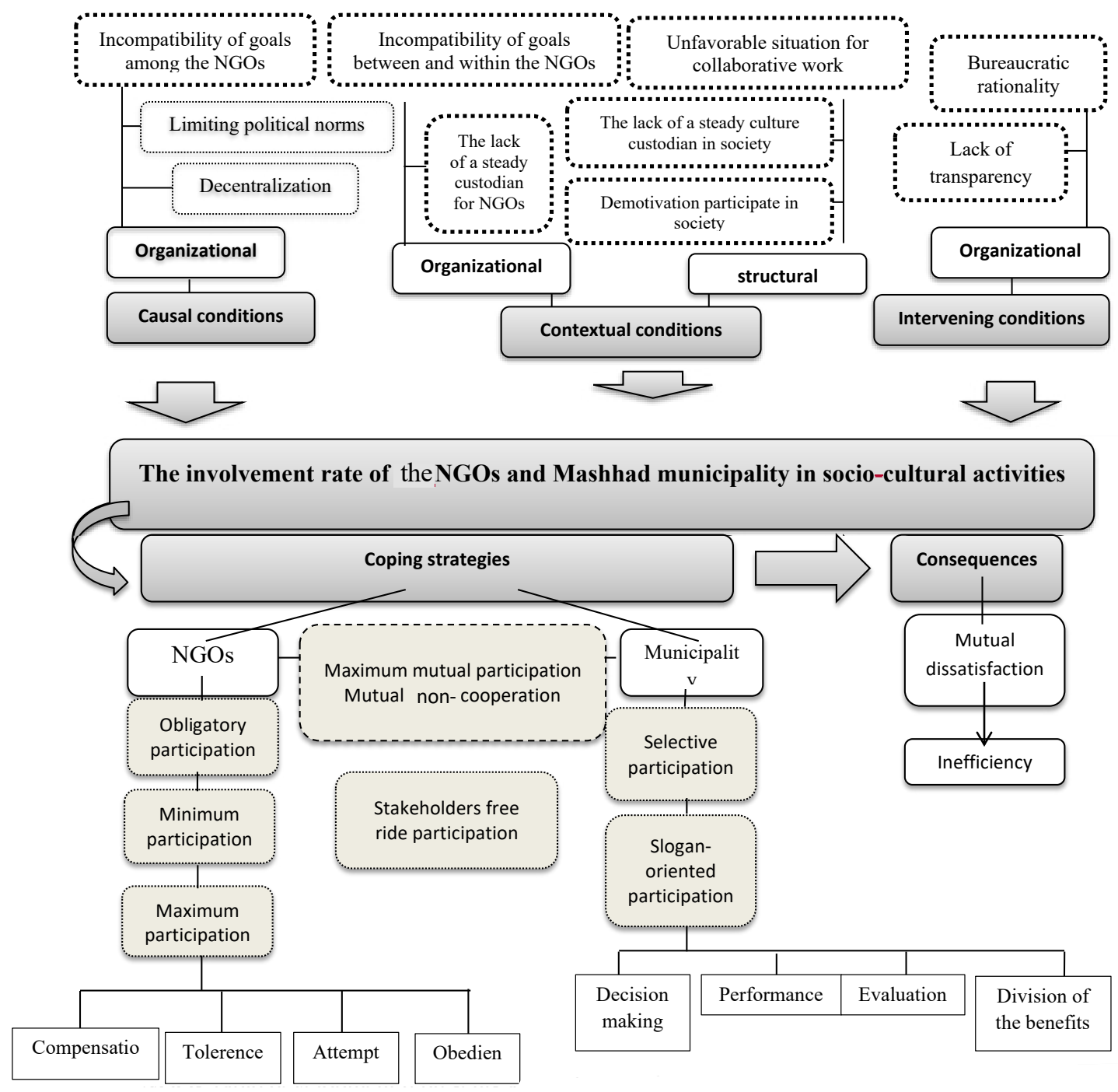

Figure 1. Final model according to Grouded theory

between the NGOs and Mashhad municipality. However, some scientists have highlighted three major weaknesses connected with this form of relationship [16].

Interview assessment showed that individuals operate in projects through NGOs, but the primary issue is that the definition of involvement obtained in this study does not match with a true and precise one. According to the present results, the slogan-oriented involvement is one of the coping strategies that the municipality employs concerning NGOs because the four phases of involvement are not fully carried out. Therefore, there is no satisfaction even at the stage of execution, indicating mutual discontent, which is a subcategory of mutual distrust between the municipal authorities.
According to the study outcomes, one of the contextual variables is the unfavorable situation for cooperative work whose subcategories are individualistic motives and individualism's precedence over collective advantages. These two variables occur in the process of individual socialization and turn into a framework where there is no motivation to do a cooperative job, as individuals prefer individualism over collectivism. Another factor is the restrictive standards, whereas NGOs are voluntary, nongovernmental, nonprofitable, charitable organizations whose nonpolitical characteristics are essential.

Unfortunately, the point of perspective and political orientation in government agencies, including the municipality has made involvement with such organizations hard, as it has caused some sort of incompatibility with 
its goals. In reality, the limited political standards of the municipality primarily cause the type of involvement and decrease it.

This problem along with the absence of the transparency of instructions troubled the type of communication. Although 26 articles of economics and the Fourth Plan of Social and Cultural Development have been assigned to enhance cooperation, attract involvement, and empower the NGOs, their efficient roles and capacities have been ignored in the country's legislation and regulations. Figure 1 represents the final research model.

\section{Conclusion}

NGOs' rapid development represents a growing trend towards expressing views and collective involvement. However, the findings of this study show that these organisations require extensive involvement and collaboration in governmental organisations, which is sadly not enough because there are many inconsistencies between their objectives according to the results.. The NGOs are non-governmental, non-profit, charitable, voluntary organizations working in particular areas. In other words, they are apolitical because they do not have the right to conduct in political activity under the name of the legal personality of their organization. On the other side, their activity is charitable, which means that their

Foundation's aim is not to gain economic income. Thus, if they have produced a profit, it should be used for the same charitable purposes. However, their performance has derailed the objectives, because they face political difficulties that are politically assessed in the involvement with governmental organizations. In this manner, numerous issues follow the offering of NGOs to society. Also, the present results showed that inequality is one of the effective subcategories. By motivating and attracting public participation, NGOs can play an efficient part in achieving the goals of the vision document.

They do not care about the extent that one of the contextual circumstances in these studies is that NGOs have no custodian and stable supporter. According to the findings, these organizations are not engaged in policy-making. One of the causes can arise from the misconception that if these organizations interfere in decision-making, they will face political penalties and consequences. Based on the study results, one of the major issues with involvement is that the engagement mechanism was not presented in upstream and downstream papers.

\section{Ethical Considerations}

\section{Compliance with ethical guidelines}

This study was approved by the Ethics Committee of Gonabad Branch, Islamic Azad University (Code No.: 34951 /د, on January 6, 2020).

\section{Funding}

This research did not receive any grant from funding agencies in the public, commercial, or non-profit sectors.

\section{Authors' contributions}

Conceptualization, data collection, and data analysis: Maryam Eskafi; Manuscript preparation: Both authors.

\section{Conflict of interest}

The authors declared no conflict of interest.

\section{References}

[1] Pourmosawi SM. [Citizen participation and leisure programs (Persian)]. Tehran: Jame'eh va Farhang publishing; 2011.

[2] Ahmadi M, Hashim HS, Mohamed AF, Moharamnehad N. Toward community-based waste management: Tehran as a case example. Middle East J Sci Res. 2013; 15(8):1102-7. https://www.idosi.org/mejsr/mejsr15(8)13/6.pdf

[3] Brass JN. Surrogates for government? NGOs and the state in Kenya [PhD. dissertation]. Berkeley, CA: University of California, Berkeley; 2010. https://escholarship.org/uc/ item/6b4157cd

[4] Graafland-Boersma R. The success of sister-city partnerships between Dutch municipalities and a municipality in a CEEC formalized between 1989-2000 [MA. thesis]. Enschede: University of Twente; 2015. https://essay.utwente.nl/68346/1/ Boersma_MA_BMS.pdf

[5] Dunmade I. Sustainability issues in rural-urban partnerships: A study on regional and inter-municipal collaborations between some Southern Alberta municipalities. Environ Ecol Res. 2014; 2(1):1-7. http:/ /www.hrpub.org/journals/article_ info.php?aid $=1006$

[6] Forsyth T. Enhancing climate technology transfer through greater public-private cooperation: Lessons from Thailand and the Philippines. Nat Resour Forum. 2005; 29(2):165-76. [DOI:10.1111/j.1477-8947.2005.00125.x]

[7] Besley T, Ghatak M. Public-private partnerships for the provision of public goods: Theory and an application to NGOs. Res Econ. 2017; 71(2):356-71. [DOI:10.1016/j.rie.2017.04.005]

[8] van Ewijk E. Between local governments and communities: Knowledge exchange and mutual learning in Dutch-Moroc- 
can and Dutch-Turkish municipal partnerships [PhD. dissertation]. Amsterdam: University of Amsterdam; 2013. https:// dare.uva.nl/search?arno.record.id $=458559$

[9] Hosseini Moghaddam SS, Fazeli AM, Davoodi Y, Jamshideh Kouhsari H. [Recognition of ways of absorption and maintenance volunteer human resources in NGOs case study: Red crescent society of Mazandaran province (Persian)]. Paper presented at: $2^{\text {nd }}$ International Conference on Management Entrepreneurship and Economic Development. 12-13 September 2013; Qom, Iran. https:/ / civilica.com/doc/286942/

[10] Mirdamadi SM, Haji-Shafie S. The perception of residence about role of Non Government Organizations (NGO's) in preserving the urban green spaces in Tehran. Int J Agric Sci Res. 2010; 1(1):25-9. http://ijasr.srbiau.ac.ir/article_1035.html

[11] Wright G, Andersson K. Non-governmental organizations, rural communities and forests: A comparative analysis of community-NGO interactions. Small-Scale For. 2013; 12:3350. [DOI:10.1007/s11842-012-9206-2]

[12] Kgosiemang DT, Oladele OI. Factors affecting farmers' participation in agricultural projects in Mkhondo municipality of Mpumalanga Province, South Africa. J Hum Ecol. 2012; 37(1):19-27. [DOI:10.1080/09709274.2012.11906445]

[13] Ghaffari G. [Urban management and social participants (Persian)]. Tehran: Tisa Publication; 2013. http://opac.nlai. ir/opac-prod/bibliographic/3193035

[14] Khorshidvand R. [Review the participation role of non governmental organization in maintaining order and security (Persian)]. Police Hum Dev. 2009; 6(25):35-44. http:// pod.jrl. police.ir/article_9408.html

[15] Alavi Moghadam MR, Mokhtarani N, Mokhtarani B. Municipal solid waste management in Rasht City, Iran. Waste Manag. 2009; 29(1):485-9. [DOI:10.1016/j.wasman.2008.02.029] [PMID]

[16] Orbista C. NGOs participation in local governance in the Philippines [MA. thesis]. Christchurch: University of Canterbury; 2012. https://ir.canterbury.ac.nz/handle/10092/8104

[17] Lekorwe M, Mpabanga D. Managing non-governmental organizations in Botswana. Innov J. 2007; 12(3):10. https:// www.researchgate.net/publication/228379806 